\title{
Numerical Investigation of a Wood-Chip Downdraft Gasifier
}

\author{
Alessandro Vulpio ${ }^{1,}$, Nicola Casari $^{1}$, Mirko Morini ${ }^{2}$, Michele Pinelli $^{1}$, and Alessio Suman ${ }^{1}$ \\ ${ }^{1}$ Università degli Studi di Ferrara, Dipartimento di Ingegneria, 44121, Via Giuseppe Saragat 1, Ferrara \\ ${ }^{2}$ Università degli Studi di Parma, Dipartimento di Ingegneria e Architettura, 43124, Parco Area delle \\ Scienze, 181, Parma
}

\begin{abstract}
Biomass gasification is regarded as one of the most promising technology in the renewable energy field. The outcome of such operation, i.e. the synfuel, can be exploited in several ways, for example powering engines and turbines, and is considered more flexible than the biomass itself. For this reason, a careful analysis of the gasification performance is of paramount importance for the optimization of the process. One of the techniques that can be used for such a purpose, is the numerical analysis. CFD is indeed a tool that can be of great help in the design and study of the operation of the gasifier, allowing for an accurate prediction of the operating parameters. In this work, a downdraft gasifier is considered, and the biomass is made of wood chip. The present analysis is devoted to build the numerical model and simulate all the reactions that happen inside an actual gasifier, considering the drying of the wood chip, heating, pyrolysis, and combustion. Good match with experimental results is found, making the numerical model here presented a reliable virtual test bench where investigating the effects of variation in the working parameters.
\end{abstract}

\section{Introduction}

Energy derived from biomass gasification becomes more and more attractive in recent years. The growing interest in this energy source comes from the combination of different factors: the interest in the reduction of greenhouse gas emissions, the local availability of the energy source and the fluctuating price of oil and natural gas [1]. Furthermore, unlike wind or solar, energy supply derived from biomass is predictable. For this reason, biomass can help renewable grids to meet energy demands without discontinuities. Gasification is a thermalchemical process that converts biomass into synthesis gas (syngas) with useful calorific value, containing $\mathrm{CO}, \mathrm{H}_{2}$ and $\mathrm{CH}_{4}$. The syngas obtained has, therefore, a high hydrogen-tocarbon $(\mathrm{C} / \mathrm{H})$ ratio and can be used as fuel to power gas turbines [2], internal combustion engines [3] and fuel cells [4]. Downdraft gasifier is one of the promising technologies that allows the conversion of biomass at small and medium scales [5,6]. In these fixed-bed devices, biomass is fed from the upper part of the gasifier while air is supplied centrally through an inlet pipe. The product of the process, such as syngas and ash, comes out from

\footnotetext{
*Corresponding author: alessandro.vulpio@unife.it
} 
the bottom of the gasifier. The particles are subjected to different thermal-chemical reactions such as drying, pyrolysis and char oxidation/gasification. Those reactions take place in different zones of the gasifier, with no well-defined boundaries among them [7]. Key aspects for the design and the optimization of gasifiers are the prediction of the syngas composition and the prediction of the temperature distribution along the reactor. For this reason, CFD modeling of downdraft gasifiers is receiving increasing attention in the last years. The set-up of a kinetic model [8] can predict the gas-solid transport phenomena and the kinetics of the reaction in each zone of the reactor. In this work, the CFD simulation of a test-case reactor from literature [9] is proposed. This test case is a downdraft gasifier fueled with woody biomass. The governing chemical reactions of the process have been taken from [10]. The aims of the work are to show the methodology of gasification modeling and to compare the results obtained on the same reactor geometry using different kinetic reaction parameters. The temperature profile along the reactor is compared with the one showed in the test case [8].

\section{Computational Model}

The downdraft gasifier has been simulated with the commercial finite volume code FLUENT [11]. The assumptions made in the study are the following:

- The flow is steady and two-dimensional;

- The feedstock is modeled with the Discrete Phase Model (DPM), according to the small dimension of the particles;

- The particles have a uniform distribution in size and shape;

- The chemical reactions are modeled with the species transport with Finite Rate/Eddie Dissipation;

- $\quad$ The radiation is modeled with the Discrete Ordinates (DO) model.

The SIMPLE algorithm is used for velocity-pressure coupling and the turbulence is modeled by $\kappa-\varepsilon$ with scalable wall functions. A second order discretization scheme is used for all calculated variables. The two-way model is used to couple momentum, heat and mass transfer between gas and solid phases. Turbulence dispersion of particles is modeled by using the Discrete Random Walk model.

\subsection{Geometry and Mesh}

The geometry of the test-case gasifier is reported in Fig.1. The assumption of an axisymmetric flow inside the reactor leads to a two dimensional model of the geometry. The total number of triangular cells in the mesh is 43,053 . An enlarged view of the grid of the nozzle and the throat is reported in Fig.1.

\subsection{Governing Equations}

The governing equations for continuity, momentum, energy, turbulent kinetic energy $\kappa$, turbulent dissipation rate $\varepsilon$ and species transport are applied to the continuous phase.

The following transport equation [11] governs the chemical reactions for the $i^{\text {th }}$ species:

$$
\frac{\partial}{\partial t}\left(\rho Y_{i}\right)+\frac{\partial}{\partial x_{j}}\left(\rho u_{j} Y_{i}\right)=\frac{\partial}{\partial t}\left(\rho Y_{i} D_{i} \frac{\partial Y_{i}}{\partial x_{j}}\right)+R_{i}+S_{i}
$$

where $Y_{i}$ is the mass fraction, $u_{j}$ is the velocity component, $D_{i}$ is the diffusion coefficient, $R_{i}$ is the reaction source term and $S_{i}$ represents the source term. The term $R_{i}$ can be written as:

$$
R_{i}=M_{w, i} \sum_{r=1}^{N_{R}} \hat{\mathrm{R}}_{i, r}
$$


where $M_{w, i}$ is the molecular weight of species $i, \hat{\mathrm{R}}_{i, r}$ is the molar rate of creation/distruction of species $i$ in reaction $r$ and $N_{R}$ is the number of reactions in which the species $i$ participates. The reaction source term for the species $i$ is governed by the stoichiometric relation for the $r^{\text {th }}$ reaction:

$$
\sum_{i=1}^{N} v_{i, r}^{\prime} M_{i} \stackrel{k_{b, r}}{\rightleftharpoons} \underset{k_{f, r}}{\Longrightarrow} \sum_{i=1}^{N} v_{i, r}^{\prime \prime} M_{i}
$$

where $\mathrm{M}$ is the symbol denoting the $i^{t h}$ species, $v_{i, r}^{\prime}$ is the stoichiometric coefficient for reactant $i$ in reaction $r, v_{i, r}^{\prime \prime}$ is is the stoichiometric coefficient for product $i$ in reaction $r$ and $N$ is the number of chemical species in the system. The molar rate of creation/distruction of species $i$ in reaction $r$ is expressed as:

$$
\hat{\mathrm{R}}_{i, r}=\Gamma\left(v_{i, r}^{\prime \prime}-v_{i, r}^{\prime}\right)\left(k_{f, r} \prod_{j=1}^{N_{r}}\left[C_{j, r}\right]^{\eta_{j, r}^{\prime}}-k_{b, r} \prod_{j=1}^{N_{r}}\left[C_{j, r}\right]^{\eta_{j, r}^{\prime \prime}}\right)
$$

where $\Gamma$ represents the effects of third bodies on the reaction rates, $C_{j, r}$ is the molar concentration of each reactant and product species $j$ in reaction $r, \eta_{j, r}^{\prime}$ is the forward rate exponent, $\eta_{j, r}^{\prime \prime}$ is the backward rate exponent and $N_{r}$ is the number of chemical species in reaction $r$. For a general reaction $r$ the forward reaction rate is written as:

$$
k_{f, r}=A_{r} T^{\beta} e^{-\frac{E_{r}}{R T}}
$$

where $A_{r}$ is the pre-exponential factor, $E_{r}$ is the activation energy and $\beta$ is the temperature exponent.
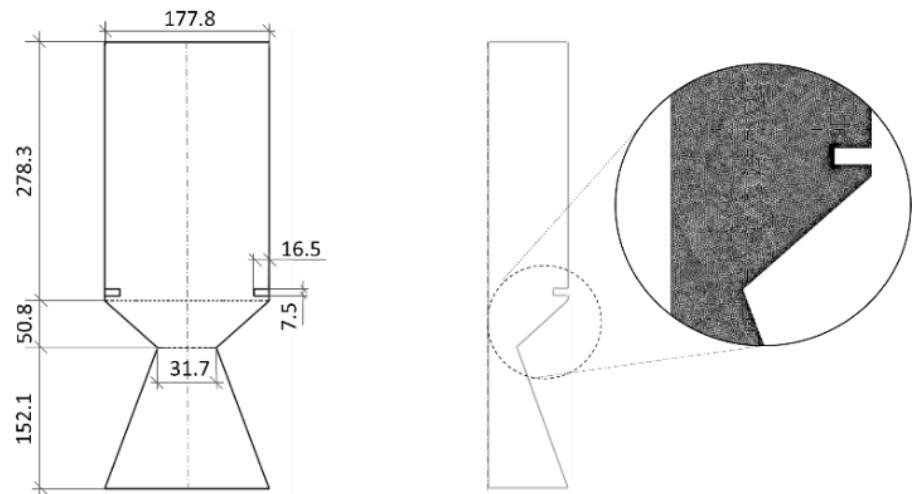

Fig.1 Schematic geometry of the test-case reactor, the fluid domain used in the CFD model and an enlarged view of the nozzle.

\subsection{Chemical Reactions Modeling}

Feedstock enters the upper part of the gasifier at $50{ }^{\circ} \mathrm{C}$. The proximate and ultimate analysis of the wood biomass used in this work is reported in Tab.1 and is taken from [9]. The wood particles are modeled as spheres of $0.1 \mathrm{~mm}$ in diameter according to the limitation of the discrete phase model. The high heating value (HHV) and the density used for biomass in the model are $18 \mathrm{MJ} / \mathrm{kg}$ and $400 \mathrm{~kg} / \mathrm{m}^{3}$, according to [9].

Table 1. Proximate and Ultimate analysis of wood. The values refer to the composition in mass [\%].

\begin{tabular}{|c|c|c|c|}
\hline $\begin{array}{c}\text { Proximate } \\
\text { Analysis }\end{array}$ & [\%] & Ultimate Analysis & {$[\mathbf{\%}]$} \\
\hline Fixed Carbons & 31.46 & Carbon & 49.59 \\
\hline Volatile & 56.39 & Hydrogen & 6.28 \\
\hline Moisture & 9.71 & Oxygen & 43.74 \\
\hline
\end{tabular}




\begin{tabular}{|l|l|c|c|}
\hline \multirow{2}{*}{ Ash } & \multirow{2}{*}{2.44} & Nitrogen & 0.39 \\
\cline { 3 - 4 } & & Sulfur & 0.00 \\
\hline
\end{tabular}

\subsubsection{Drying}

Evaporation of water is the first step involving biomass feedstock at the top of the reactor. The content of moisture contained in biomass needs to be evaporated before continuing the gasification. The energy invested in the water vaporization is not recoverable and for this reason, this process is not negligible in gasification modeling. The reaction of water evaporation from wood is modeled using the wet combustion model provided in FLUENT [11].

\subsubsection{Pyrolysis}

The pyrolysis represents the step in which biomass is devolatilized. The products of pyrolysis are gases $\left(\mathrm{CO}, \mathrm{H}_{2}, \mathrm{H}_{2} \mathrm{O}\right.$ and $\mathrm{CH}_{4}$ ), liquids (tar) and solid (char). In this step, no external agent is needed. This process is typically carried out in a temperature range of $300^{\circ} \mathrm{C}-650{ }^{\circ} \mathrm{C}$. The volatiles release from the wood particle is modeled with the single kinetic rate model:

$$
-\frac{d m_{p}}{d t}=k\left[m_{p}-\left(1-f_{v, 0}\right)\left(1-f_{w, 0}\right) m_{p, 0}\right]
$$

where $m_{p}$ is the mass of the particle, $f_{v, 0}$ is the mass of volatiles initially present in the particles, $f_{w, 0}$ is the mass fraction of evaporating material and $k$ is the kinetic rate constant and $m_{p, 0}$ is the initial mass of the particle. The pre-exponential factor and the activation energy of the devolatilization process are taken from [12] and are respectively $10^{8} \mathrm{~s}^{-1}$ and 140 $\mathrm{kJ} / \mathrm{mol}$. The scheme provided by FLUENT is used to model the volatiles decomposition. The presence of TAR is not considered in the present analysis.

\subsubsection{Char Oxidation and Gasification}

The products of pyrolysis involve homogeneous and heterogeneous reactions that take place in the throat of the reactor. Gasification reactions are for the most part endothermic. However, to provide the required heat to trigger drying and pyrolysis processes, exothermic reactions of combustion inside the gasifier are allowed [1].To model these reactions the multiple surface reaction model is provided [11]. The reactions list provided to model gas-phase (GP) and solid-phase (SP) reactions is reported in Tab. 2. In Tab.2 the values of pre-exponential factor $\left(A_{r}\right)$, activation energy $\left(E_{r}\right)$ and temperature exponent $(\beta)$ are also reported.

Table 2. Reaction kinetics of gas-phase (GP) and solid-phase (SP) reactions in the gasification process.

\begin{tabular}{|c|c|c|c|c|c|}
\hline \multicolumn{2}{|c|}{ Reaction } & $A_{r}\left(\mathrm{~s}^{-1}\right)$ & $E_{r}(\mathrm{~kJ} / \mathrm{mol})$ & $\beta$ & Reference \\
\hline $2 \mathrm{CO}+\mathrm{O}_{2} \rightarrow 2 \mathrm{CO}_{2}$ & $(\mathrm{R} 1-\mathrm{GP})$ & $1.30 \mathrm{e}+11$ & 126.0 & 0 & {$[13]$} \\
\hline $2 \mathrm{H}_{2}+\mathrm{O}_{2} \rightarrow 2 \mathrm{H}_{2} \mathrm{O}$ & $(\mathrm{R} 2-\mathrm{GP})$ & $3.50 \mathrm{e}+08$ & 30.5 & 0 & {$[13]$} \\
\hline $\mathrm{CO}+\mathrm{H}_{2} \mathrm{O} \rightarrow \mathrm{CO}_{2}+\mathrm{H}_{2}$ & $(\mathrm{R} 3-\mathrm{GP})$ & 0.0265 & 65.8 & 0 & {$[14]$} \\
\hline $\mathrm{C}+\mathrm{O}_{2} \rightarrow \mathrm{CO}_{2}$ & $(\mathrm{R} 4-\mathrm{SP})$ & $5.67 \mathrm{e}+09$ & 160.0 & 0 & {$[14]$} \\
\hline $2 \mathrm{C}+\mathrm{O}_{2} \rightarrow 2 \mathrm{CO}$ & $(\mathrm{R} 5-\mathrm{SP})$ & $7.92 \mathrm{e}+04$ & 218.0 & 0 & {$[14]$} \\
\hline $\mathrm{C}+\mathrm{CO}_{2} \rightarrow 2 \mathrm{CO}$ & $(\mathrm{R} 6-\mathrm{SP})$ & $5.89 \mathrm{e}+02$ & 223.0 & 1 & {$[13]$} \\
\hline $\mathrm{C}+2 \mathrm{H}_{2} \rightarrow \mathrm{CH}_{4}$ & $(\mathrm{R} 7-\mathrm{SP})$ & $1 \mathrm{e}+11$ & 42.0 & 0 & {$[14]$} \\
\hline
\end{tabular}




\begin{tabular}{|l|l|l|l|l|l|}
\hline $\mathrm{C}+\mathrm{H}_{2} \mathrm{O} \rightarrow \mathrm{CO}+\mathrm{H}_{2}$ & $(\mathrm{R} 8-\mathrm{SP})$ & 5.714 & 65.8 & 1 & {$[13]$} \\
\hline
\end{tabular}

\subsection{Boundary Conditions}

The boundary conditions are based on literature data $[9,12,14]$ for wood gasification in downdraft reactors. Four values of Equivalence Ratio (ER), between 0.19 and 0.43 , have been tested. The mass flow rate value of feedstock is set at $0.011 \mathrm{~kg} / \mathrm{s}$ for all the simulations while the air flow rate changes according to the ER. The stoichiometric ratio of air to wood is $6: 1$. The boundary condition at the bottom of the reactor has been modeled as an outflow. The heat exchange on the wall is modeled with mixed convection and radiation condition. The physical constants of fiberglass are used to model the insulation section [9].

\section{Results}

The work of Janajreh et al. [9] provides a comparison between experimental measures on the reactor and CFD results. In Fig..2.a the comparison between the temperature profiles taken from [9] and the temperature profile obtained in the present work is reported. The temperature profiles are obtained for an Equivalence Ratio of 0.24.
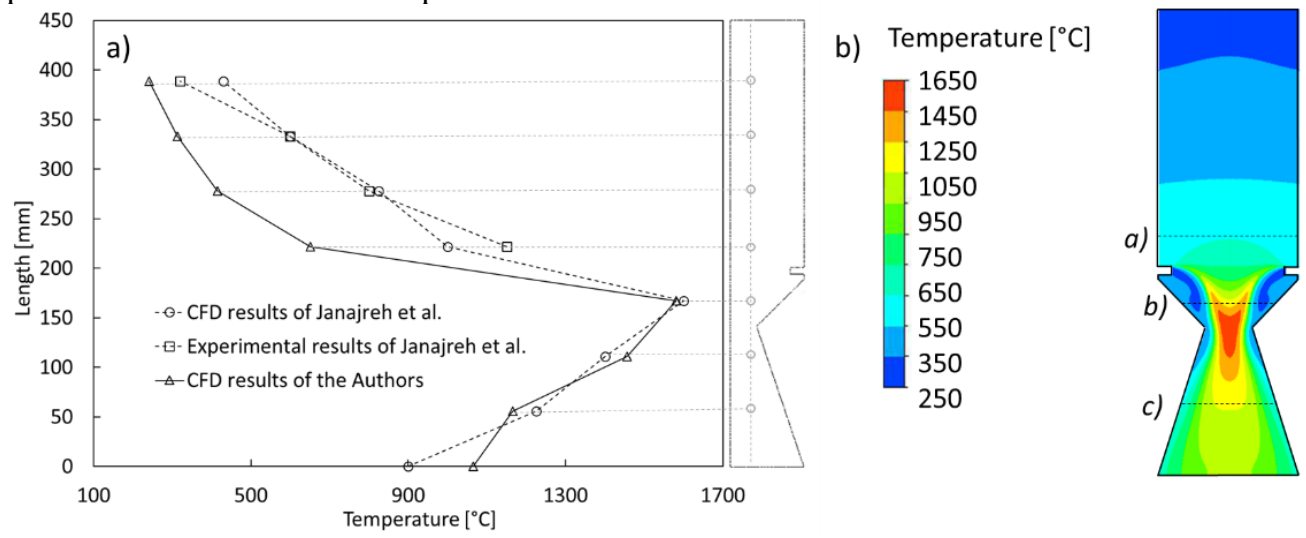

Fig. 2 a) Comparison between the temperature profiles of [9] and the temperature profile obtained in the present work, b) contour of the temperature inside the reactor for an ER of 0.24.

As shown in Fig.2.a the increasing of temperature starts at the top of the gasifier when moisture release begins. As expected, the highest temperature value is reached in the zone of the throat where combustion reaction takes place. The results of the present work underestimate the temperature values in the upper part of the reactor. This is due to the different reactions used in this work with respect to those in [9]. The contour of the temperature inside the reactor is reported in Fig.2.b. Three of the most significant zones of the reactor have been highlighted: zone a) indicates the end of the drying process, zone b) indicates the end of devolatilization and zone c) represent the reduction zone. Four different values of Equivalence Ratio, 0.19, 0.24, 0.31 and 0.43, have been simulated. In Fig. 3 four temperature profiles, one for each ER value, have been plotted. The peaks of the temperature profiles are located in the zone of the throat. The difference between the four conditions lies in the gas exit temperature: the higher the Equivalence Ratio, the lower is the outlet gas temperature. 


\section{Conclusion}

In this paper, the numerical analysis of a wood-chips downdraft gasifier is provided. A test case taken from literature has been simulated with an alternative set of reactions. Finally, the results have been compared with the experimental measurements on the reactor. The methodology followed to set up the numerical analysis is reported in detail. The simulation found a good agreement with the experimental data, confirming the reliability of the numerical model.

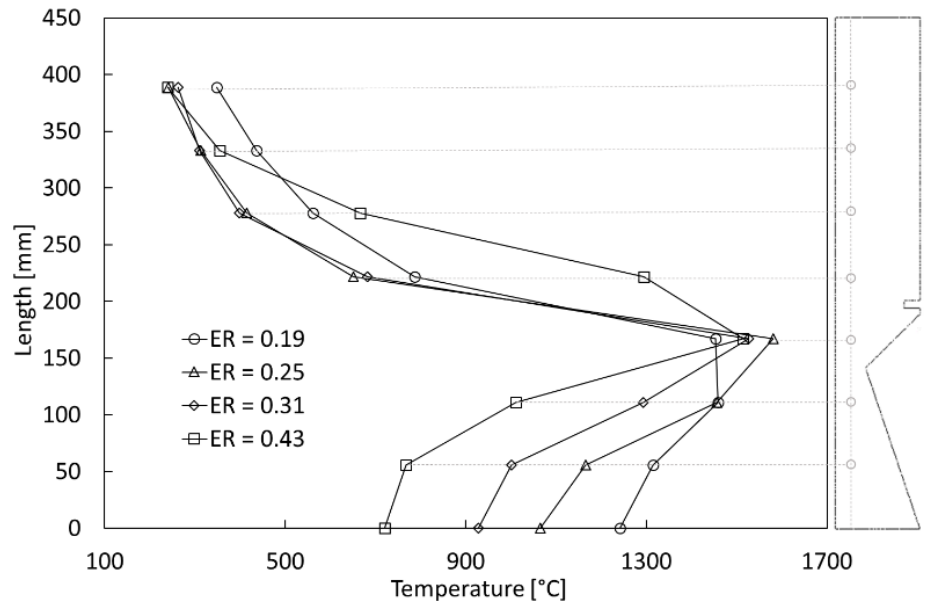

Fig. 3 Temperature profiles along the reactor axis for the four different values of ER.

The work was carried out within the framework of the research project "SYNBIOSE - Gassificazione di biomasse lignocellulosiche in sistemi di cogenerazione di piccola taglia $(200 \mathrm{~kW})$ per applicazioni nel settore terziario" (CUP G96G16000800003) funded by "Cassa per i servizi energetici e ambientali" within the call "Bando di gara per progetti di ricerca di cui all'art. 10, comma 2, lettera b) del decreto 26/1/2000, previsti dal Piano triennale 2012-2014 della ricerca di sistema elettrico nazionale e dal Piano operativo annuale 2013."

\section{References}

1. P. Basu, Biomass gasification and pyrolysis: practical design and theory (Academic Press, 2010).

2. M. Cadorin, M. Pinelli, A. Vaccari, R. Calabria, F. Chiariello, P. Massoli, and E. Bianchi, Journal of Engineering for Gas Turbines and Power 134, 071401 (2012).

3. J. D. Mart'inez, K. Mahkamov, R. V. Andrade, and E. E. S. Lora, Renewable Energy 38, 1 (2012).

4. R. Suwanwarangkul, E. Croiset, E. Entchev, S. Charojrochkul, M. Pritzker, M. Fowler, P. Douglas, S. Chewathanakup, and H. Mahaudom, Journal of Power Sources 161, 308 (2006).

5. Z. Zainal, A. Rifau, G. Quadir, and K. Seetharamu, Biomass and Bioenergy 23, 283 (2002).

6. M. Dogru, C. Howarth, G. Akay, B. Keskinler, and A. Malik, Energy 27, 415 (2002).

7. Y. Richardson, M. Drobek, A. Julbe, J. Blin, and F. Pinta, in Recent advances in thermochemical conversion of biomass (Elsevier, 2015), pp. 213-250.

8. Y. Wang and C. Kinoshita, Solar energy 51, 19 (1993).

9. I.Janajreh and M. Al Shrah, Energy Conversion and Management 65, 783 (2013).

10. P. Meenaroch, S. Kerdsuwan, and K. Laohalidanond, Energy Procedia 79, 278 (2015).

11. Ansys Fluent 15 (2013)

12. W.-C. R. Chan, M. Kelbon, and B. B. Krieger, Fuel 64, 1505 (1985).

13. Y. Wu, Q. Zhang, W. Yang, and W. Blasiak, Energy \& Fuels 27, 3274 (2013).

14. C. Di Blasi, Chemical engineering science 55, 2931 (2000). 